\title{
SPECIAL DIVINE ACTS: \\ THREE PSEUDO-PROBLEMS AND A BLIND ALLEY
}

\author{
ROBERT LARMER
}

University of New Brunswick

\begin{abstract}
Traditionally, special divine acts have been understood as involving intervention in the course of nature, so as to cause events that nature would not, or could not, otherwise produce. The concept of divine intervention has come under heavy fire in recent times, however. This has caused many philosophers and theologians either to abandon the possibility of special divine acts or to attempt to show how such acts need not be understood as interventions in natural processes. This paper argues that three objections typically raised against special divine acts conceived as interventions in the natural order are pseudo-problems and pose no reason to abandon the traditional conception of such acts. Further, it argues that attempted noninterventionist accounts constitute a blind alley of investigation, inasmuch as they fail to provide a secure foundation for a robust account of the possibility of special divine acts.
\end{abstract}

\section{INTRODUCTION}

Traditionally, special divine acts have been understood as involving intervention in the course of nature, so as to cause events that nature would not, or could not, otherwise produce. The concept of divine intervention has come under heavy fire in recent times, however. This has caused many philosophers and theologians either to abandon the possibility of special divine acts ${ }^{1}$ or attempt to show how such acts need not be conceived as interventions in natural processes. ${ }^{2}$ This paper

\footnotetext{
${ }^{1}$ Maurice Wiles, for example, was prepared to abandon the category of special divine acts writing that 'the primary usage for the idea of divine action should be in relation to the world as a whole rather than to particular occurrences within it'. Maurice Wiles, God's Action in the World (London: SCM, 1986), p. 28.

${ }^{2}$ Robert J. Russell, perhaps the foremost proponent of NIODA (non-interventionist objective divine action), argues that "because of developments in the natural sciences,
} 
argues that three objections typically raised against special divine acts conceived as interventions in the natural order are pseudo-problems and pose no reason to abandon the traditional conception of such acts. Further, it argues that purported noninterventionist accounts are a blind alley inasmuch as they fail to provide a secure foundation for a robust account of the possibility of special divine acts.

\section{FIRST PSEUDO-PROBLEM}

A frequent objection to mind-body dualism is that it is inconceivable that there can be any causal relation between material and immaterial substances. We find, for example, Richard Taylor insisting 'that as soon as the smallest attempt at any description is made [of how an immaterial mind could act on a physical body] the description becomes unintelligible and the conception an impossible one. ${ }^{3}$ It thus comes as no surprise that Arthur Peacocke, critical of the idea that mind-body dualism might provide resources for conceiving God's relation to the world, writes that,

it is [...] difficult to imagine how God might be an agent in [the] world [... if] the only analogy for such agency has itself been formulated in dualistic terms that involve a gap dividing action in the 'body', and so in the natural world, from intentions and other acts of the 'mind'. This is an ontological gap between two kinds of entities across which it is difficult to see how in principle a bridge could be constructed. ${ }^{4}$

In much the same vein, David Corner claims that if the supernatural entities that are supposed to have causal efficacy in the natural world

including quantum physics, genetics, evolution, and the mind/brain problem, and because of changes in philosophy, including the move from epistemic reductionism to epistemic holism and the recognized legitimacy of including whole-part and top-down analysis, we can now view special providence as consisting in the objective acts of God in nature and history [...] and we can interpret these acts in a non-interventionist manner consistent with the natural sciences".

Robert J. Russell, Cosmology: From Alpha to Omega (Minneapolis: Fortress Press, 2008), pp. 111-112.

${ }^{3}$ Richard Taylor, Metaphysics, 2nd ed. (New Jersey: Prentice-Hall, 1974), p. 25. In a similar vein, Jaegwon Kim writes, 'just try to imagine how something that isn't anywhere in physical space can alter in the slightest degree the trajectory of even a single material particle in motion.' Jaegwon Kim, Philosophy of Mind (Boulder, Colorado: Westview Press, 1998), p. 4.

${ }^{4}$ Arthur Peacocke, Theology for a Scientific Age (Oxford: Blackwell, 1998), p. 148. 
are conceived as being too different from natural entities, it will be hard to say how there can be any causal interaction between nature and the supernatural. ${ }^{5}$

Much can be said by way of reply to this objection, but in the context of a short paper it suffices to make two points. First, the suggestion that we cannot imagine how it is possible for an immaterial entity to causally affect the material world ignores the fact that all basic causal relations are, in the final analysis, conceptually opaque. ${ }^{6}$ Even in cases of causation in the physical world, we have at the most fundamental level no account of how one thing causes another. Brian Ellis is correct to remind us that,

sooner or later, in the process of ontological reduction, we must come to events and processes that are not themselves structures of constituent causal processes. These most elementary causal processes [...] will consist entirely of elementary events [...] the identities of the basic causal interaction that initiate and terminate elementary causal processes [...] cannot depend in turn on their causal structures. ${ }^{?}$

We may, for example, become familiar with the fact that masses attract one another. We may even give the name of gravity to the fact that they do so, and describe gravity as one of the fundamental processes of nature. To the degree that it is fundamental, however, there can be no account of how it is the case that masses can attract each other, no specification of a mechanism by which this happens, only the observation that they in fact do so. ${ }^{8}$ Given, then, that all causal relations are in the final analysis conceptually opaque, there is no more difficulty in thinking such relations can exist between immaterial and material entities than in thinking they can exist between material entities. ${ }^{9}$ In both cases, as William Hasker

${ }^{5}$ David Corner, The Philosophy of Miracles (London: Continuum, 2007), p. 42.

${ }^{6}$ For a fuller discussion see Robert Larmer, The Legitimacy of Miracle (Lanham, Maryland: Lexington Press, 2014), pp. 105-108, 155-159.

${ }^{7}$ Brian Ellis, Scientific Essentialism (Cambridge: Cambridge University Press, 2001), p. 51 .

${ }^{8}$ An anonymous critic has suggested that despite conceptual opacity we rightly recognize constraints on causation and that one of the constraints is that 'like-can-onlycause-like'. Such a constraint, however, cannot be simply assumed without begging the question against the dualist. For the difficulties in justifying such a claim see John Foster, The Immaterial Self (London: Routledge, 1991), pp. 159-163.

9 To claim that direct divine causal intervention is causally opaque is not to claim that what are recognized as special divine acts, say the Virgin Birth, can have no natural processes associated with them. As C. S. Lewis notes, "If God annihilates or creates or deflects a unit of matter He has created a new situation at that point. Immediately all 
observes, 'we have no ultimate insight into the causal relations involved, except to say, "That's the way things are." 10

Second, the objection appears to prove too much. If successful, it demonstrates not only that the idea of divine intervention is incoherent, but that the idea of a creator God is incoherent, since if an immaterial God cannot stand in a causal relation to a material world He can scarcely be viewed as its creator and sustainer. Such an objection, therefore, requires that one be prepared to argue that the existence of the material world logically implies that even if God exists He cannot be thought to have created the world, that is to say, the doctrine of creation ex nihilo is logically incoherent. Arguments in support of such an ambitious and counter-intuitive claim are not in evidence, and it would be an understatement to suggest that it is difficult to think how they could be formulated. I conclude, therefore, that objections to special divine acts conceived as divine interventions in nature based on the purported difficulty of holding there cannot be causal relations between immaterial and material entities pose a pseudo-problem.

\section{SECOND PSEUDO-PROBLEM}

A second objection that is routinely raised against special divine acts understood as interventions in the course of nature is that such interventions would violate the Principle of the Conservation of Energy. William Stoeger speaks for many when he writes that

direct divine intervention [...] would involve an immaterial agent acting on or within a material context as a cause [...] This is not possible [...] if

\footnotetext{
Nature domiciles this new situation, makes it at home in her realm, adapts all other events to it. It finds itself conforming to all the laws. If God creates a miraculous spermatozoon in the body of a virgin, it does not proceed to break any laws. The laws at once take it over. Nature is ready. Pregnancy follows, according to all the natural laws, and nine months later a child is born. [...] If events ever come from beyond Nature [...] she will [... not] be incommoded by them. [... She will] hasten to accommodate the newcomer. The moment they enter her realm they obey all her laws. Miraculous wine will intoxicate, miraculous conception will lead to pregnancy [...] miraculous bread will be digested. The divine art of miracle is not an art of suspending the pattern to which events conform but of feeding new events into that pattern." C. S. Lewis, Miracles (First published 1947. Reissued London: Fontana, 1974), pp. 63-64.

10 William Hasker, The Emergent Self (Ithaca, New York: Cornell University Press, 1999), p. 150.
} 
it were $[\ldots]$ energy $[\ldots]$ would be added to a system spontaneously and mysteriously, contravening the conservation of energy. ${ }^{11}$

Such an objection, however, ignores a crucial ambiguity in how the Principle is formulated. It is typically stated as either 'Energy can neither be created nor destroyed, ${ }^{12}$ or as 'In an isolated system the total amount of energy remains constant', the assumption being that these two statements are logically equivalent. This assumption is false. If one claims that 'Energy can neither be created nor destroyed' then one must also claim that 'In an isolated system the total amount of energy remains constant'. To claim, however, that 'In an isolated system the total amount of energy remains constant ${ }^{13}$ does not commit one to the claim that 'Energy can neither be created nor destroyed. The latter claim involves a much greater metaphysical commitment than the former.

It is important that these two formulations of the Principle not be conflated. Theists cannot accept the claim that energy can neither be created nor destroyed, since it not only rules out divine intervention but creation ex nihilo. If the universe is conceived to be composed of forms of energy that can neither be created nor destroyed, then one pays the compliment of necessary existence to energy rather than to God, and there is no sense in which God can be conceived as being the cause of the existence of the physical order. ${ }^{14}$

11 William Stoeger, 'Describing God's Action in the World in Light of Scientific Knowledge of Reality', in Chaos and Complexity: Scientific Perspectives on Divine Action, edited by Robert John Russell, Nancey Murphy, and Arthur Peacocke. (Jointly published by the Vatican Observatory Foundation and The Center for Theology and the Natural Sciences, 1995), pp. 239-61 (p. 244). Also, Willem Drees, 'Gaps for God', in Chaos and Complexity: Scientific Perspectives on Divine Action, edited by Robert John Russell, Nancey Murphy, and Arthur Peacocke. (Jointly published by the Vatican Observatory Foundation and The Center for Theology and the Natural Sciences, 1995), pp. 225227. Unsurprisingly, similar objections are frequently made concerning the possibility of mind-body interaction. See, for example, Daniel Dennett, Consiousness Explained (Boston: Little, Brown \& Co., 1991), p. 35.

12 Sheldon Glashow, From Alchemy to Quarks (U.S.A.: ITP, 1994), p. 104.

${ }^{13}$ Kenneth Krane, Modern Physics, 2nd ed. (U.S.A.: Wiley, 1996), p. 4.

${ }^{14}$ Nicholas Saunders fails to appreciate this point when he dismisses the importance of distinguishing between the two forms of the Principle, arguing that it is [...] not reasonable to make retrospective claims concerning the limitation of divine freedom in creating the world out of nothing on the basis of a set of laws which have only evolved due to its establishment'. Nicholas Saunders, Divine Action and Modern Science (Cambridge, Cambridge University Press, 2003), p. 74. It is one thing to claim that God 
Theists, however, need have no difficulty accepting the claim that energy is conserved in an isolated system. Accepting this claim commits them not to rejecting that there is good evidence that energy is conserved to the degree that a system is causally isolated, but rather to rejecting the speculative claim that the physical universe is an isolated system not open to the causal influence of God. In short, theists are in a position to affirm the Principle when it is formulated as a scientific law and not as a metaphysical commitment which excludes the possibility of creation ex nihilo. ${ }^{15}$

What this means is that, so long as there is good reason to accept the scientific rather than the metaphysical form of the Principle, there can be no basis upon which to generate a balance of probabilities argument opposing evidence which supports belief in divine intervention and evidence which supports belief in the Principle. The theist denies not that energy will be conserved in an isolated system, but that the physical universe is in fact an isolated system. Accepting the occurrence of divine intervention in nature does not commit the theist to denying the vast body of experimental evidence supporting the claim that energy will be conserved in an isolated system, but rather to denying the far more speculative claim that the universe is isolated in the sense of not being open to the causal influence of God. As Alvin Plantinga comments in an extravagant but telling example,

it is entirely possible for God to create a full-grown horse in the middle of Times Square without violating the principle of the conservation of energy. That is because the systems including the horse would not be closed or isolated. For that very reason, there would be no violation of

could create a world that has a different material nature than our own, and consequently a different set of laws. It is quite another, however, to claim that God could accomplish the logically impossible task of creating something (energy) which can neither be created nor destroyed. Contra Saunders, the point is not whether physical laws can be thought of as coming into existence with the Big Bang, but whether the claim that energy can neither be created nor destroyed is logically inconsistent with the claim of creation ex nihilo.

15 Ducasse, writing in 1951, failed to distinguish between the two forms of the Principle. He saw clearly, however, the implications of the claim that energy can neither be created nor destroyed, when he noted that the Principle of the Conservation of Energy is something one has to have if, as the materialistic ontology of [...] naturalism demands, one is to be able to conceive the physical world as wholly self-contained, independent, isolated'. Curt Ducasse, Nature, Mind, and Death (La Salle, Ill.: Open Court Publishing, 1951), p. 241. 
the principle of conservation of energy, which says only that energy is conserved in closed or causally isolated systems - ones not subject to any outside influence. It says nothing at all about conservation of energy in systems that are not closed; and, of course, if God created a horse ex nihilo in Times Square, no system containing that horse, including the whole of the material universe, would be closed. ${ }^{16}$

It bears emphasis that any attempt to move from the well-evidenced claim energy is conserved in an isolated system to the claim that the universe is in fact an isolated system is ill-founded. All that any experiment can be thought to show is that, to the degree that a system is isolated, the amount of energy in it is conserved. Such evidence is neutral as regards the further question of whether there exists an entity capable of creating or destroying energy. If the move from the claim that energy is conserved in an isolated system to the claim that energy can neither be created nor destroyed were to be justified, it would have to be on the grounds that there exists no evidence that energy is ever created or destroyed and that the claim that energy can neither be created nor destroyed constitutes a deep structural explanation of why energy is conserved in an isolated system. Any such attempted justification fails on several counts.

First, the theist is able to provide an alternative deep structural explanation of the fact that energy is conserved to the degree that a system is causally isolated. The theistic conception of the universe as a contingent reality in which secondary physical causes operate equally explains why the scientific form of the Principle holds true. It will not do, therefore, for the critic to suggest that the claim that energy can neither be created nor destroyed is the only possible deep structural explanation of energy conservation in isolated systems.

Second, the claim that energy can neither be created nor destroyed is at odds with our best cosmological theory, namely the Big Bang. This theory is commonly interpreted as implying an absolute beginning to the mass/energy that composes the universe. ${ }^{17}$ It is possible to accept both the claim that energy is conserved in an isolated system and an absolute beginning to the universe, but it is hard to see how acceptance of the claim that energy can neither be created nor destroyed is consistent with

${ }^{16}$ Alvin Plantinga, Where the Conflict Really Lies (Oxford: Oxford University Press, 2011), p. 79.

17 Robert Spitzer, New Proofs for the Existence of God (Grand Rapids, Michigan: Eerdmans, 2010), pp. 13-104. 
Big-Bang cosmology, since it would imply that the mass/energy making up the universe had no beginning.

Third, the claim that energy can neither be created nor destroyed, cannot be used as the basis upon which to frame a balance of probabilities argument designed to show conflict between the positive evidence taken to support belief in the Principle and the evidence in favour of special divine acts. Acceptance of the claim that energy can neither be created nor destroyed requires, at the very least, that there exists no positive evidence that energy is ever created or destroyed. The occurrence of special divine acts, conceived as events involving the creation or annihilation of energy, conflicts not with any positive experimental evidence supporting belief that energy is conserved to the degree that a system is isolated, but rather with the negative claim that there is no evidence for events involving the creation or destruction of energy. Faced with reports of special divine acts, the occurrence of which would arguably constitute evidence that energy can be created or destroyed, it begs the question to dismiss such reports as antecedently improbable on the grounds that they imply the falsity of the claim that energy can neither be created nor destroyed. One cannot rule out there being mice in the building on the grounds that there is presumably no evidence of their presence, and then refuse to accept reports of tracks, scat, and sightings on the basis that one has already established that there are no mice in the building. ${ }^{18}$ Similarly, one cannot urge that the claim that energy can neither be created nor destroyed be accepted on the basis that this has never been observed, and then use one's acceptance of that claim to rule out the occurrence of special divine acts, on the grounds that such events would constitute evidence that energy can be created or destroyed.

It is evident, therefore, that attempts to move from the well-evidenced claim that to the degree that a physical system is causally isolated its energy will be conserved, to the speculative claim that energy can neither be created nor destroyed, cannot be justified. The claim that energy can neither be created nor destroyed is at odds with our best cosmological theories, begs the question of whether special divine acts occur, and

${ }^{18}$ An anonymous critic has objected that the charge of question begging is premature, since it might turn out that the people reporting tracks, scat, and sightings are mistaken or unreliable. This objection, however, misses the point. It is one thing to assess how strong the positive evidence is, quite another to dismiss the possibility of considering such positive evidence on the question begging assumption that one has already established that it does not exist. 
a priori rules out the possibility of theism being true. It functions not as a well-evidenced statement of observed regularity in nature but rather as an unfounded defining postulate of physicalism. I conclude, therefore, that objections to special divine acts, understood as divine interventions in nature, based on the claim that such events would violate the Principle of the Conservation of Energy pose a pseudo-problem.

\section{A BLIND ALLEY}

Concerned to cleave to the mistaken claim that the amount of energy must remain constant in the universe on pain of violating the Principle of the Conservation of Energy, thinkers such as Nancey Murphy, John Polkinghorne, and Arthur Peacocke have attempted to show how special divine acts can occur within an energetically closed universe, not by an input of energy but by an input of information, and that such acts need not be conceived as interventions. Although such attempts have become de rigueur, they appear incapable of delivering what they promise. I shall briefly describe these attempts and some very specific problems with each of them. I shall then mention a fundamental problem which plagues all three and which, quite independently of the various specific problems, appears to doom such efforts to failure. The conclusion to be drawn is that such attempts fail to secure any kind of foundation for a robust defence of the possibility of special divine acts. They constitute, therefore, a blind alley which defenders of special divine acts would do well to avoid.

\section{Murphy's Special Divine Acts as Exploiting Quantum Indeterminacy}

Nancey Murphy's account of special divine agency takes quantum indeterminacy as providing inherent gaps in the natural order - what William Pollard termed 'loopholes' ${ }^{19}$ - in which God may be conceived as having room to operate. In her view, although subatomic entities have inherent powers, God's action is required if these powers are to be actualized. ${ }^{20}$ Thus every quantum event requires a specific intentional act

19 William Pollard, Chance and Providence (New York: Scribner, 1958), p. 8.

${ }^{20}$ Nancey Murphy, 'Divine Action in the Natural Order: Buridan's Ass and Schrödinger's Cat', in Chaos and Complexity: Scientific Perspectives on Divine Action, edited by Robert John Russell, Nancey Murphy, and Arthur Peacocke. (Jointly published 
of God as its determining cause. ${ }^{21}$ There is no need, however, to conceive of God as competing with natural causes, since at the subatomic level natural causes are insufficient to determine all outcomes. ${ }^{22}$ God's agency, on this model, is the hidden variable which underlies the apparent indeterminacy of quantum processes. ${ }^{23}$

There are a number of problems which suggest that the approach taken by Murphy is unsatisfactory. A major concern is that it is unclear how the quantum processes of the microworld relate to events in the macroworld. Murphy's epistemology appears to be one of critical realism, yet the standard Copenhagen interpretation of quantum mechanics which she adopts, is usually linked to an extreme instrumentalism. As Lawrence Osborn notes, on the Copenhagen interpretation,

the probabilities generated by the Schrödinger wave equation do not correspond to any physical reality. There simply is no reality to be described until an act of measurement collapses the wave function. Quantum mechanics is merely a useful calculating device for predicting the possible outcomes of such acts of measurement. ${ }^{24}$

It is difficult to see how Murphy's claim that God acts on microphysical entities in such a manner that one quantum state rather than another is realized, can be made consistent with an interpretation of quantum physics which holds that prior to an act of measurement such entities do not exist.

A further concern is that quantum indeterminacies at the microlevel 'dampen out' to deterministic regularities at the macrolevel. In order for quantum indeterminacy to make a difference to how events unfold in the world there must be some means of amplifying the effect of particular quantum indeterminacies. ${ }^{25}$ This implies, however, that models of divine

by the Vatican Observatory Foundation and The Center for Theology and the Natural Sciences, 1995), pp. 325-57 (p. 344).

${ }^{21}$ Ibid., p. 339.

${ }^{22}$ Ibid., p. 343.

${ }^{23}$ Ibid., p. 342.

${ }^{24}$ Lawrence Osborn, 'Theology and the New Physics', in God, Humanity and the Cosmos, ed. by Christopher Southgate (Harrisburg, Pennsylvania: Trinity Press International, 1999), pp. 95-136 (p. 115).

${ }_{25}$ Thomas Tracy, 'Particular Providence and the God of the Gaps', in Chaos and Complexity: Scientific Perspectives on Divine Action, edited by Robert John Russell, Nancey Murphy, and Arthur Peacocke. (Jointly published by the Vatican Observatory Foundation and The Center for Theology and the Natural Sciences, 1995), pp. 291-324 (p. 317). Also, Thomas Tracy, 'From Quantum Physics to Theology', in Philosophy, Science 
agency which seek to exploit quantum indeterminacy are radically incomplete, unless they can also account for the means by which particular quantum effects are amplified.

The most natural candidate, indeed perhaps the only candidate, for providing a means of amplifying the effects of quantum events seems to be chaotic systems. There are many problems with such a suggestion but it suffices to mention two.

First, a major, but frequently ignored, problem for those attempting to develop a model of divine agency based on integrating quantum indeterminacy and chaos theory is that quantum theory seems to imply that chaos cannot occur. According to quantum theory, systems described by the Schrödinger equation are not capable of exhibiting the type of sensitive dependency on their initial state characteristic of chaotic systems. We have at present no resolution of the problem of how to reconcile quantum theory and chaos theory and no solution seems apparent on the horizon. ${ }^{26}$ Given this state of affairs, any suggestion that the modus operandi of divine agency in creation is the amplification of quantum events by means of chaotic systems seems ill-considered.

Second, even if this difficulty is ignored, nature is not nearly so chaotic as is required if chaos theory, combined with quantum indeterminacy, is to provide a foundation for a robust account of special divine acts. Jeffrey Koperski puts the point well when he writes that

even if we grant that most systems are nonlinear (and therefore possibly chaotic), aperiodicity and randomness are dynamical characteristics that often reside in the midst of perfectly regular evolutions. Chaos, like background noise, is routinely ignored and rightly so. [...] To put it crudely, [such an account of special divine action] describes a causal pathway in which God could alter the arrangement of bubbles in the crest of a tsunami but not redirect its course. Presumably more is wanted from an account of divine agency. ${ }^{27}$

\section{Polkinghorne's Special Divine Acts as Exploiting Chaotic Systems} Whereas Murphy focuses upon quantum indeterminacy as providing a loophole in natural processes by which God might be provided a way

and Divine Action, edited by F. LeRon Shults, Nancey Murphy, and George Ellis (Boston: Brill, 2009), p. 208.

${ }^{26}$ Jeffrey Koperski, 'God, Chaos and the Quantum Dice', Zygon, 35:3 (2000), 555-556.

27 Ibid., p. 556. Also, Jeffrey Koperski, The Physics of Theism (West Sussex, UK: Wiley Blackwell, 2015), p. 177. 
to perform special divine acts, John Polkinghorne appeals to chaotic systems as providing such an opportunity. Polkinghorne thinks that it is theologically significant that chaotic systems are extremely sensitive and thus inherently unpredictable. In his view, the epistemological uncertainty inherent in attempting to predict the behaviour of chaotic systems, suggests that such systems are ontologically open. Given their ontological openness, God may causally influence their behaviour. $\mathrm{He}$ does so not by an input of energy, but by a 'top down' input of information. ${ }^{28}$ This suggestion that God achieves particular purposes through the instrumentality of chaotic systems does not, however, Polkinghorne insists, relegate God to acting in the role of an unpredictable quantum event. He writes,

the significance of the sensitivity of chaotic systems to the effect of small triggers is diagnostic of their requiring to be treated in holistic terms and of their being open to top-down causality through the input of active information. It is not proposed that this is the localized mechanism by which agency is exercised. [...] that either we or God interact with the world by [...] adjustment of infinitesimal details of initial conditions so as to bring about a desired result. ${ }^{29}$

God's providential particular acts are thus situated within theism's broader doctrine of creation.

Apart from the already noted difficulty that the amount of chaos present in nature appears to place unacceptable restraint on what God may actually accomplish in terms of special acts by exploiting chaotic systems, Polkinghorne's proposal faces a major obstacle inasmuch as it is far from clear that his move from epistemological indeterminacy to ontological indeterminacy can be justified. The equations typically used to model chaotic systems are deterministic and physicists generally conceive chaotic systems as determined. Thus Wesley Wildman and Robert Russell argue that

chaos in nature gives no evidence of any metaphysical openness in nature. The fact that a natural dynamical system is open to its environment, which

${ }^{28}$ John Polkinghorne, Belief in God in an Age of Science (New Haven: Yale University Press, 1998), pp. 62-63.

${ }^{29}$ John Polkinghorne, 'The Metaphysics of Divine Action', in Philosophy, Science and Divine Action, edited by F. LeRon Shults, Nancey Murphy, and George Ellis (Boston: Brill, 2009), p. 106. 
is sometimes described in terms of a whole/part causal relationship, does not entail metaphysical openness, for the entire environment may be causally determined [...] Sensitive dependence - a feature of chaotic dynamical systems in mathematics - is attributed to natural systems on the basis of the power of mathematical dynamical systems to model them. To the extent that this modeling works [...] the natural presupposition is that the (metaphorical) 'determinism' of mathematical chaotic dynamical systems corresponds to the metaphysical determinism of nature. Put bluntly, [sensitivity to the altering of conditions] testifies to the high degree of causal connectedness in certain natural systems and so is most naturally exploited in support of the thesis of metaphysical determinism..$^{30}$

Polkinghorne has responded by suggesting that the unwillingness to opt for the ontological indeterminacy of chaotic systems 'stems from the fact that a theory of this kind has not yet been formulated in any detail, whilst the alternative interpretation of "deterministic chaos" [...] has the timehonoured equations of classical dynamics as its rigorous articulation. ${ }^{31}$ He goes on to argue that,

it is, however, mathematically possible to enlarge the class of solutions that will be admitted, in order to include what are called non-integrable solutions. [...] A holistic account is then necessary and at the same time a rigid determinism is no longer present. ${ }^{32}$

His reply, however, has the appearance of special pleading, inasmuch as he is unable to appeal to any scientific, as opposed to specifically theological reasons, for thinking that chaotic systems are best modelled non-deterministically.

\section{Peacocke's Special Divine Acts as Instances of Top-Down Causality}

The late Arthur Peacocke, in commenting on appeals to 'unpredictability, open-endedness and flexibility' as making possible non-interventionist special divine acts, makes the point that the possibility that God works

${ }^{30}$ Wesley Wildman and Robert Russel, 'Chaos: A Mathematical Introduction with Philosophical Reflections', in Chaos and Complexity: Scientific Perspectives on Divine Action, edited by Robert John Russell, Nancey Murphy, Arthur Peacocke. (Jointly published by the Vatican Observatory Foundation and The Center for Theology and the Natural Sciences, 1995), pp. 49-90 (p. 82).

${ }^{31}$ John Polkinghorne, Belief in God in an Age of Science, p. 65.

${ }^{32}$ Ibid., pp. 65-66. 
undetectably by influencing quantum events or chaotic systems does not escape an interventionist conception of such acts. He writes,

such a conception of God's action in these, to us, unpredictable situations would [...] be no different in principle from the idea of God intervening in a deterministic, rigidly law-controlled, mechanistic order of nature [...] the only difference, on this view, would seem to be that, given our irreducible incapacity to predict the histories of natural systems, God's intervention (for that is what it would properly have to be called) would always be hidden from us. ${ }^{33}$

Peacocke's own model of divine agency is grounded in his account of what it is to be a person. Rejecting any dualist account of the mind/ body relation as inherently unscientific, he insists that "mental events" in human beings are the internal descriptions we offer of an actual total state of the brain itself and are not events in some entity called the "mind" which exists in some other non-physical mode that is ontologically distinct from matter and "interacts" (mysteriously, one would have to say) with the brain as a physical entity. ${ }^{34}$ Appealing to the concept of supervenience, he holds that there are various levels of description of brain events and processes and that there are no bridge laws by which higher levels of description can be reduced to lower levels. Thus we can describe a particular event in the brain at a lower level of description as a series of neuron firings and also at a higher level of description as a conscious decision to perform an action. This means that 'the language we use concerning the connections between our mental experiences the language of reasons, intentions, and so forth - really does [...] refer to actual causal linkages. ${ }^{35}$ The threat of reductionism is thus avoided without having to posit any gap in the operation of physical causes. Analogously, God's agency within creation can be seen as operating at a supervenient level that does not necessitate abandoning the principle that the physical realm is energetically closed. ${ }^{36}$ Although he insists that 'God's action is on the world-as-a-whole ${ }^{37}$ he maintains that such action 'can be general or particular in its effects. ${ }^{38}$ Presumably, then, room can

${ }^{33}$ Arthur Peacocke, Theology for a Scientific Age, pp. 154-155.

${ }^{34}$ Ibid., p. 60.

${ }^{35}$ Ibid., p. 61

${ }^{36}$ Ibid., p. 153.

${ }^{37}$ Ibid., p. 163.

${ }^{38}$ Ibid., p. To the best of my knowledge, Peacocke simply asserts that this is the case, giving no argument for his claim. 
be made for special divine acts. Such acts, however, 'would never be observed by us as a divine "intervention", that is, as an interference with the course of nature and as a setting aside of its observed relationships. ${ }^{39}$

Peacocke's account of the person is a nonreductive physicalist one which countenances the emergence of new causal powers such that topdown causality is possible. As we have noted, he views God's relation to the world as analogous to his account of the mind-body relation, ${ }^{40}$ arguing that we should conceive of God not as separate from the universe but as comprising a higher-level supervening upon the natural processes of the universe. ${ }^{41}$ An issue which he never addresses, however, is that this line of thinking most naturally suggests that God depends upon the world to exist, rather than the world depending upon God to exist. Perhaps he would not have been happy with taking the analogy in this direction, but it is the direction which his view of the mindbody relation as analogous to the God-world relation most obviously suggests, as is attested by the tendency of those opting for nondualistic, noninterventionistic accounts of divine agency to reject classical theism and its doctrine of creatio ex nihilo in favour of panentheism. ${ }^{42}$ Certainly we see in Peacocke a preference for the idea of divine emanation rather than the idea of divine making, ${ }^{43}$ and a move from classical theism to panentheism.

Of further concern is Peacocke's overly optimistic espousal of the reality of emergent irreducible causal powers, ignoring the fact that while supervenience may guarantee semantic irreducibility, it does not entail causal autonomy. ${ }^{44} \mathrm{He}$ holds that,

(1) analysis of complex systems reveals the ontological reality of higher-level properties which exert genuine irreducible causal influence upon lower-level properties, and

(2) higher-level properties are generated by virtue of their realization in a particular configuration of lower-level properties. ${ }^{45}$

${ }^{39}$ Ibid.

40 Arthur Peacocke, Creation and the World of Science (Oxford: Clarendon Press, 1979), pp. 133-139.

${ }^{41}$ Arthur Peacocke, Theology for a Scientific Age, p. 159.

${ }^{42}$ See, for example, Ian Barbour, Religion and Science: Historical and Contemporary Issues (San Francisco: Harper, 1997), pp. 306-12.

${ }^{43}$ Arthur Peacocke, Theology for a Scientific Age, pp. 168-169.

${ }^{44}$ Dennis Bielfeldt, 'Can Western Monotheism Avoid Substance Dualism?', Zygon, 36:1 (March 2001), 153-77 (p. 170).

${ }^{45}$ Arthur Peacocke, Theology for a Scientific Age, pp. 54-55. 
appearing not to have noticed that these two claims are inconsistent. The relation of higher-level properties to lower-level properties is one of dependency with no new causal powers being created. Top-down causation is not, therefore, something that a nonreductive physicalist account of the person can accept. On such theories, the causal powers of higher-level properties are wholly dependent upon the causal properties of the lower-level properties by which they are realized. This means that whatever causes lower-level properties to be instantiated also causes higher-level properties to be instantiated; the result being that any given instance of higher-level properties will enter into exactly the same causal relations that its corresponding instance of lower-level properties enter into. As Kim observes,

there are no new causal powers that magically accrue to [upper-level] properties over and beyond the causal powers of [lower-level] properties. No new causal powers emerge at higher levels, and this goes against the claim [...] that higher-level properties are novel causal powers irreducible to lower-level properties. ${ }^{46}$

Peacocke's appeal to the emergence of genuine irreducible higher-level causal powers cannot, therefore, be justified. ${ }^{47}$

\section{A General Problem for Non-Interventionist Accounts of Special Divine Acts}

We have noted various specific problems with the typical strategies of attempting to conceptualize special divine acts in a non-interventionist way. All are motivated by what I have argued is a pseudo-problem, namely the concern that divine intervention in nature would violate the Principle of the Conservation of Energy. To make room for the possibility of special divine acts, they all suggest that God may perform such acts not by an input of energy, but rather by an input of information.

This suggestion, however, is vulnerable to the objection that all instances of information input into physical systems have energetic implications. ${ }^{48}$ Thus, for example, in the analogy provided by Peacocke of a program controlling the electronic changes in a computer, it is clear that the writing and storing of the program has energetic implications. Also, it is evident that the program will only function in conjunction

\footnotetext{
${ }^{46}$ Jaegwon Kim, Philosophy of Mind (Boulder, Colorado: Westview Press, 1998), p. 232.

47 Bielfeldt puts the point nicely when he writes that 'semantic irreducibility does not entail causal autonomy'. 'Can Western Monotheism Avoid Substance Dualism?', p. 170.

${ }^{48}$ Willem Drees, 'Gaps for God', p. 226.
} 
with a computer, that is to say, an intelligently designed artefact which itself is a product of the imposition of structure on physical components. Further, even if we ignore the fact that the intelligent structuring of the program and the computer has energetic implications, it is clear that the desired output is produced by the program and computer together constituting the initial boundary conditions under which energy flows take place. This suggests a deistic rather than theistic model of God's relation to the world. On Peacocke's analogy, God must be conceived as the master programmer who achieves his purposes through setting the initial boundary conditions under which subsequent physical processes occur without any further input. Only if we think of the programmer as continuing to interact with his program and computer can the analogy accommodate a theistic model of God's relation to creation that includes special divine acts. This, however, implies the type of intervention that Peacocke refuses to contemplate; the result being that his analogy counts against rather than for his account of how non-interventionist special divine acts are presumed to be possible.

To his credit, Peacocke does not duck the point that the input of information into the physical universe by God would have energetic implications. Acknowledging this, he writes

so we still have a problem of the 'causal joint', now in the form of: How can God exert his influence on, make an input of information into, the world-as-a-whole without an input of matter/energy? This seems to me to be the ultimate level of the 'causal joint' conundrum, for it involves the very nature of the divine being in relation to that of matter/energy and seems to me to be the right place in which to locate the problem, rather than at some lower levels in the created order at which divine 'intervention' would then have to be postulated with all of its difficulties. ${ }^{49}$

Besides constituting an admission that he has no answer to the problem of how information could be added to the universe without any energetic implications, this passage highlights that, despite claiming that his account could allow for special divine acts, Peacocke's model of divine agency in creation is essentially deistic, presenting no worked out account of how it is consistent with the occurrence of special divine acts.

Consideration of these three typical strategies, as exemplified by Murphy, Polkinghorne, and Peacocke, suggests that purported

\footnotetext{
${ }^{49}$ Arthur Peacocke, Theology for a Scientific Age, p. 164.
} 
non-interventionist accounts of the possibility of special divine acts are in fact a blind alley. In the case of Murphy and Polkinghorne, we are offered not a non-interventionist account of special divine action, but rather the claim that such intervention will always lie hidden in 'those, to us, uncloseable gaps in the predictability of the natural world. ${ }^{50}$ In the case of Peacocke, as we have seen, he avoids intervention only at the price of offering a deistic account of God's relation to the world.

\section{THIRD PSEUDO-PROBLEM}

A third pseudo-problem lurking in discussion of the possibility of special divine acts is the largely unexamined assumption that there must exist some causal indeterminacy in natural processes in which God may be thought to have room to operate. Otherwise, the view seems to be, special divine acts would either not be possible or would imply violating the laws of nature. Thus Pollard, whose seminal Chance and Providence has had great influence on the contemporary discussion of the possibility of special divine acts, takes causal indeterminacy in nature to be a necessary condition of such acts, since otherwise there is 'extraordinary difficulty [...] in imagining any kind of loophole through which God could influence [events]; [... no] point in the world [...] at which the hand of God could be thrust in and providence [...] actually exercised'. ${ }^{51}$ Similarly, Robert Russell takes for granted that if nature does not exhibit ontological indeterminism then special divine acts would imply violation of the laws of nature. ${ }^{52}$

But why think this? The question of whether a system is deterministic in how it functions must be distinguished from the question of whether it is causally closed. It is entirely possible for an external agent to influence what happens in a deterministic system, without violating the laws operating in the system. One does not break any of Newton's laws of motion if one tosses an extra billiard ball into the mix, yet one alters the outcome of what would otherwise occur on the table. If God changes the material conditions to which the laws apply, He thereby produces an event that nature would not have produced on its own, but violates no laws of nature. Robert Young aptly makes this point when he writes that

\footnotetext{
${ }^{50}$ Ibid., p. 154.

${ }^{51}$ William Pollard, Chance and Providence (New York: Scribner, 1958), p. 8.

${ }^{52}$ Robert Russell, Cosmology: From Alpha to Omega (Minneapolis, MN: Fortress, 2008), p. 127.
} 
God is an active agent-factor in the occurrence of [... special divine acts] such that his presence introduces a new (possibly unique) set of causally sufficient factors. His presence ceteris paribus alters the outcome from what it (perhaps) would have been if, contrary to fact, he had not been present. Here there is no sense of violation or physical impossibility, [or] mere coincidence. ${ }^{53}$

It is thus clear that whether the physical universe exhibits causal indeterminacy or, as even some interpretations of quantum mechanics require, is deterministic in its functioning, God as its Creator, is capable of acting upon it. It is true that if God brings about an event that would not otherwise occur there will be an explanatory gap in terms of natural causes, ${ }^{54}$ but such a gap is best understood as the result of God's action, not the prerequisite of it. To insist otherwise undermines any robust conception of special divine acts inasmuch as it sets immensely restrictive limits on what God can be thought to be able to bring about. It is only the insistence by non-interventionists that the physical universe be understood as causally closed that requires them to hold that special divine action is impossible in the absence of genuine indeterminacy in how nature functions, and that such action must be constrained to the very narrow limits allowed by such indeterminacy. This insistence is far from warranted in light of the fact that no scientific theory requires that the universe be conceived as causally closed and that the result of such insistence is a view of special divine acts that allows God 'to alter the arrangement of bubbles in the crest of a tsunami but not redirect its course. ${ }^{55}$

\section{CONCLUSION: TO ACT IS TO INTERVENE}

At the beginning of this paper, it was noted that special divine acts have traditionally been understood as involving intervention in the course

${ }^{53}$ Robert Young, 'Miracles and Physical Impossibility', Sophia, Vol. 11, No. 3 (1972), 29-35 (p. 33).

54 Tracy, whose position is similar to Murphy's, nevertheless sees this point clearly, writing that 'if we affirm that God performs particular actions which affect the course of events in the world, then it certainly appears that we must also grant that there will be gaps in the explanation of these events in the sciences'. Thomas Tracy, 'Particular Providence and the God of the Gaps', in Chaos and Complexity: Scientific Perspectives on Divine Action, p. 323.

${ }^{55}$ Jeffrey Koperski, 'God, Chaos and the Quantum Dice', p. 557. 
of nature so as to cause events that nature would not, or could not, otherwise produce. Indeed, the very meaning of the word 'act' seems to imply that such acts must be conceived as interventions. To act in the midst of an ongoing historical process is precisely to intervene in the sense of producing an event that would not otherwise occur. If I act to hang a picture on the wall of my room then I intervene to bring about a state of affairs that would not otherwise occur. If Jesus acts to multiply loaves and fishes to feed a hungry crowd he intervenes to bring about a state of affairs that would not otherwise happen. This being the case, it seems a contradiction in terms to speak of 'noninterventionist special divine acts. ${ }^{56}$

Polkinghorne is correct when he insists that if the insights of a providence at work in human lives and in universal history, are to carry the weight of meaning that they do in Christian tradition and experience, then they must not simply be pious ways of speaking about a process from which particular divine activity is in fact absent and in which the divine presence is unexpressed, save for a general letting-be. ${ }^{57}$ Christian philosophers and theologians need to defend special divine acts. They

\footnotetext{
${ }^{56}$ Such a conclusion could, perhaps, be avoided if one were to embrace a thoroughgoing determinism such that all events are uniquely determined by the initial conditions God puts in place at the creation of the physical universe. Suggesting such a possibility comes at the considerable cost of ruling out free will and making the problem of evil vastly more difficult. There is also the issue of whether such a suggestion is scientifically credible, given the nature of the physical universe; the question being not whether God could possibly create a universe in which front-loading could work, but whether it could work in this actual universe. Thus Michael Chaberek notes: "The question that faces the concept of front-loading, also known as 'evolution projected by God' is whether the vision of watchmaker creating watches able to form new watches is really better than the vision of someone who personally and directly affects his works. One may also wonder whether the world as we know it, with its strict laws and physical limitations really allows one to create watches which produce other watches, and whether less advanced watches can produce greater and more complex watches. In the world we live in, we do not encounter watches capable of making other watches at all, just as we do not find engineers trying to design self-assembling cars. It is not that engineers choose to design car factors of self-assembling cars only because of their inadequate intelligence or lack of skill. Rather the constraints of objective reality make them create factories instead of self-assembling devices. One can even say that this approach actually testifies to their contrivance and comes from a clear distinction between what is possible in our world and what is a mere futuristic fantasy." Michael Chaberek,. O.P. 'Seeking the Truth about Theistic Evolution, Animal Death, and Intelligent Design.' In More than Myth?, ed. by Paul D. Brown and Robert Stackpole (U.S.A.: Chartwell, 2014), pp. 135-157 (p. 154).

${ }^{57}$ John Polkinghorne, Belief in God in an Age of Science, p. 49.
} 
should do so, however, in full recognition that the objections typically raised to conceiving special divine acts as interventions in nature constitute pseudo-problems, and that proposed noninterventionist accounts - quite apart from the fact that they seem a contradiction in terms - have all proven a blind alley, incapable of providing a secure foundation for a robust conception of special divine acts. 